\title{
Tradução, mito e tragicidade: a primazia do estético em Samuel Beckett
}

\author{
Julia de Vasconcelos Magalhães Pinto
}

UFMG

Resumo: Este artigo pretende analisar as relações entre tradução, mito e tragicidade na obra de Samuel Beckett, especialmente em O Inominável. A partir das reflexões de Walter Benjamin, pretende-se mostrar que a concepção de linguagem do escritor irlandês ultrapassa a dimensão comunicativa e instrumental para se realizar como um exercício constante de reconhecimento e tentativa de superação dos próprios limites da língua, dando origem, finalmente, ao que se denomina aqui de "estética trágica".

Palavras-chave: Beckett, Benjamin, tradução, mito, estética trágica.

\begin{abstract}
This article analyzes the relationships between translation, myth and the tragical aspect of Samuel Beckett's work, specially in The Unnamable. Based on Walter Benjamin's thought, this work aims to show how this Irish writer conception of language goes beyond the communicative and instrumental dimension in the direction of a constant exercise of recognition as well as an attempt to overcome the limitations of language itself, to finally reach what we call here the "tragic aesthetic."
\end{abstract}

Key-words: Beckett, Benjamin, translation, myth, tragic aesthetics.

\section{Walter Benjamin e o problema da tradução}

No ensaio "Sobre a linguagem em geral e sobre a linguagem do homem", Benjamin descreve uma "concepção burguesa da linguagem", e que a concebe como uma forma de comunicação especificamente humana, onde as coisas são nomeadas, sendo a palavra o seu meio. A linguagem, assim, se reduz aos signos estabelecidos por convenções arbitrárias. Esse caráter meramente instrumental desconsidera o seu paradoxo essencial. Dizer que não podemos representar nada para além da linguagem não altera o fato de não ser possível conceber uma total 
ausência da linguagem e, mais ainda, que a linguagem não possa se expressar, absolutamente, nela própria. Assim, “o homem é, entre todos os seres dotados de espírito, o único cuja essência espiritual é plenamente comunicável"i porque essa "essência espiritual” só se comunica plenamente na linguagem, e não através ou pela linguagem. Aqui, numa concepção oposta àquela associada por Benjamin à mentalidade burguesa, a linguagem deixa de ser meio para ser uma espécie de coisa-em-si, coincidindo com o próprio ser da linguagem, o próprio nome, ou o nome próprio.

Se a linguagem das coisas não comunica a sua essência, mas a sua essência-linguística, essência-linguagem, ao mesmo tempo pode-se dizer que o nome é para a linguagem a sua própria essência, seu absoluto. Benjamin estabelece uma equivalência entre "essência espiritual" e "essência linguística", o que aponta para uma teoria metafísica da linguagem, mas também para uma filosofia da linguagem e da religião. Se as coisas e a natureza possuem uma linguagem muda e a sua essência só pode ser uma "essência linguística", elas só comunicam sua essência na linguagem, enquanto que o nome é a "imediatidade na comunicação do concreto" ii que o homem abandonou em prol do "abismo da tagarelice", da crença na função mediadora da palavra, após a expulsão do paraíso e a quebra da continuidade ontológica em relação a Deus.

A separação entre a linguagem e as coisas decorre da expulsão do homem do paraíso. A Queda é que inaugura a pluralidade e a confusão entre as línguas. ${ }^{i i i}$ A quebra da unidade Deus, homem e natureza, decorrente da expulsão do paraíso, está na origem do relativismo linguístico e da incessante necessidade de tradução, simbolizados pelo mito de Babel. A tradução, portanto, estaria ligada a uma tentativa melancólica de resgate de uma língua primordial, essa que, por ser intraduzível e impossível, é exatamente o que possibilita, ad infinitum, a tradução. A impossibilidade, de qualquer língua, de comunicar a essência das coisas é, paradoxalmente, o que requer a tradução e a torna não apenas possível, mas necessária. Ela é ainda mais necessária quando consideramos que a tradução, que caminha sempre em direção à "pura língua", promove uma elevação do original, mesmo que, de fato, ela não esteja ao alcance de nenhuma língua em particular. Segundo Benjamin, em "A tarefa do tradutor":

$\mathrm{Na}$ tradução, o original cresce e se alça a uma atmosfera mais elevada e mais pura da língua, onde, é claro, não poderá viver por muito tempo, da mesma forma como está bem longe de 
alcançá-la em todas as partes de sua figura, mas a qual, de modo extraordinariamente penetrante, ele ao menos alude, indicando o âmbito predestinado e interdito da reconciliação e plenitude das línguas. Jamais o original o alcança de uma vez por todas: mas nele está o que numa tradução ultrapassa a comunicação. ${ }^{\text {iv }}$

Benjamin afirma que a tradução literal, que visa somente à comunicação, acaba por se tornar uma "transmissão inexata de um conteúdo inessencial", já que o essencial se encontra exatamente no que não se comunica, mas que se revela na linguagem e, mais ainda, na passagem das línguas. Interessa, aqui, demarcar este sentido que existe fora da literalidade e que se encontra além (ou aquém) da comunicação e o caráter absolutamente estrangeiro da linguagem. Pois se a tradução apresenta esta estranheza ao tradutor, é simplesmente porque não há, até mesmo na sua própria língua, uma correspondência unívoca entre as palavras e as coisas.

\section{A estética trágica de Samuel Beckett}

Na obra do escritor e dramaturgo irlandês Samuel Beckett, há um deslocamento de uma estética do trágico para uma estética trágica, do luto pela constatação do fracasso da linguagem para a elevação da linguagem, ao mais alto grau de seu fracasso, e, portanto, da sua tragicidade, agora, estética. Fazer a linguagem silenciar e fracassar, sem uma nostalgia da nomeação, essa é a

tarefa paradoxalmente impossível e almejada por Beckett - uma "literature of the non-word"vi - e que se mantém como impossibilidade, sem desmoronar, sem se desconstruir, mas, pelo contrário, se mantendo nessa tensão mesma. Ainda a partir de Benjamin, em "A linguagem em geral e a linguagem dos homens", "em todo luto, há uma profunda inclinação para a ausência de linguagem, o que é infinitamente mais do que uma incapacidade ou uma aversão a comunicar". Assim, "aquilo que é triste sente-se conhecido de parte a parte pelo incognoscível"vii . A tristeza, assim, estaria na possibilidade de nomeação. Se a tristeza estaria, também, ainda como supõe Benjamin, na sobrenomeação, na pluralidade das línguas, que torna a tradução, talvez não impossível, mas trágica—já que é a própria impossibilidade que a torna possível—Beckett subverte essa relação transformando a impotência e impossibilidade em uma linguagem que se quer muda. 
Assim, trata-se de uma busca, não por uma linguagem que não comunique nada, mas que, pelo contrário, que comunique tudo. E não o tudo da natureza e das coisas, mas de si mesma, que seja o seu próprio fracasso. Benjamin afirma, nesse mesmo texto (2011), que a linguagem não é apenas comunicação, já que também é capaz de revelar aquilo que não se comunica. A linguagem de Beckett, assim, não coincide com os signos, não se encerra na sua função comunicativa nem apenas na denúncia dessa impossibilidade, mas aponta para a possibilidade máxima de comunicar; e só ela é capaz disso, de comunicar o absolutamente incomunicável.

Se "a linguagem de um ser é o meio em que a sua essência espiritual se comunica"viii, poderíamos, a partir de Beckett, entender essa afirmação de Benjamin como: a linguagem é o meio pelo qual os $N o t I^{i x}$ se comunicam. A linguagem não apenas nomeia a essência muda das coisas, mas também revela, em si mesma, o que a ela escapa, a saber, the unnamable. Se a linguagem não coincide com o signo, ela tampouco se encerra no seu fracasso, e o seu maior paradoxo, de ser o que aprisiona e, ao mesmo tempo, a única possibilidade de salvação, é um paradoxo que não é resolvido e nem mesmo desconstruído na obra desse escritor. Não é um motivo de lamentação como não o é de aniquilamento. A tragicidade de Beckett é, antes, resposta estética à dessacralização do mundo e, também, uma negação da desconstrução completa. O que resta, para além do fracasso, não é o nada, tampouco é apenas linguagem - já que "the words fail"x xi -, mas o para além dela que se revela nela mesma. Um silêncio "full of murmurs"xii , que, ao tentar ultrapassar a mera comunicação - que é "all lies",xii -, não desiste, não sucumbe ao fracasso, mas eleva esse inominável à beleza estética.

Essa estética que identifico em Beckett ultrapassa a crise moderna, mas também não se circunscreve na pós-modernidade. Estando, assim, neste entre-lugar, essa estética não se encerra numa nostalgia de uma linguagem que de fato nomeie, e não reduz a experiência humana a mero signo. O que vemos na obra desse escritor é, por outro lado, um retorno ao mito - enquanto dimensão caracterizada, ao mesmo tempo, pela irredutibilidade filosófica e pelo constante convite à interpretação, conforme sugere Ricœur (2009). Na poética de Beckett, é possível identificar uma primazia da tradução, de modo a afirmar o fracasso de todas as línguas como única possibilidade de se alcançar algo que escapa a todas.

The Unnamable nos apresenta essa estranheza inescapável, já que somos colocados lado a lado com esses "eus", não personagens, todos "foreigners in an unfamiliar land"xiv . Suas 
palavras, estrangeiras, estranhas, parecem estar construindo uma narrativa que não cansa de se desconstruir, como vemos na passagem a seguir:

Having nothing to say, no words but the words of others, I have to speak. No one compels me to, there is no one, it's an accident, a fact. Nothing can ever exempt me from it, there is nothing, nothing to discover, nothing to recover, nothing that can lessen what remains to say, I have the ocean to drink, so there is an ocean then ${ }^{\mathrm{xv}}$.

Não há, aqui, uma negação da linguagem, mas uma afirmação do seu fracasso e, por isso mesmo, na sua capacidade de apresentar o inefável, o inominável, como se pudéssemos "speak and yet say nothing, really nothing [?]"xvi . Se a comunicação fracassa e a impossibilidade se apresenta, há uma recusa, ao mesmo tempo, de ser tragado pelo inominável, de desistir de nomear: "I'11 never know, in the silence you don't know, you must go on, I can't go on, I'1l go on"xvii.

\section{Tradução: O mito enquanto palimpsesto}

A relação entre tradução e mito, como sendo a manifestação suprema do palimpsesto pode nos servir como uma analogia, aqui. Gerárd Genette (1930) observa em Palimpsestos: $a$ literatura de segunda mão que o objeto da poética não é o texto em si, que só pode ser tomado em sua historicidade, o que podemos associar com a ideia de "sobrevida" em Benjamin, que está estreitamente relacionada com a sua concepção de tradução. ${ }^{\text {xviii }}$ Genette aponta para uma transcendência textual, uma espécie de arqueologia do texto, por uma analogia com os palimpsestos, que também pode nos ser útil pra pensar o mito:

Um palimpsesto é um pergaminho cuja primeira inscrição foi raspada para se traçar outra, que não a esconde de fato, de modo que se pode lê-la por transparência, o antigo sob o novo. Assim, no sentido figurado, entenderemos por palimpsestos (mais literalmente hipertextos), todas as obras derivadas de uma outra obra anterior, por transformação ou por imitação. Dessa literatura de segunda mão, que se escreve através da leitura o lugar e a ação no campo literário geralmente, e lamentavelmente, não são reconhecidos. Tentamos aqui explorar esse território. 
Um texto pode sempre ler um outro, e assim por diante, até o fim dos textos. Este meu texto não escapa à regra: ele a expõe e se expõe a ela. Quem ler por último lerá melhor. ${ }^{\text {xix }}$

Nesse sentido, para Genette, todo texto literário é potencialmente "hipertexto", já que carrega em si textos anteriores. Essa "sobrevida" que um texto confere a outro é, por outro lado, já, também, uma tradução dele. A literatura carrega em si mesma uma relação com o mito ou, ainda, o mito só se apresenta como tradução, já que o acesso a um mundo pré-linguagem nos é interditado. Dessa forma, não haveria um mito original, uma vez que toda tentativa de comunicálo já é em si uma tradução, já é linguagem. Ele é, por si próprio, intraduzível, não se circunscreve a uma narrativa única e é, pela sua impossibilidade de se traduzir, sempre ainda traduzível. O mito se faz narrar, por não se deixar narrar, é apreensível e revelador exatamente por escapar a qualquer tentativa de circunscrição a uma verdade única. E é, aqui, que aproximamos o mito da noção de Benjamin de "língua pura", como uma pré-linguagem, fundadora, mas inalcançável, próxima à palavra sagrada, portanto, que pode ser revelada, mas não representada.

A estética de Beckett não é uma estética do trágico, porque não se deixa tragar pelo desencantamento do mundo nem pelo aniquilamento da linguagem que o segue. Ela é uma estética trágica porque não nega a tragédia, mas eleva a linguagem ao seu próprio fracasso. Se a linguagem não é capaz de revelar o ser, que dela escapa, ao mesmo tempo, só o vislumbre absoluto do seu fracasso é capaz de revelar o "não ser", que escapa ao próprio ser, mas não à linguagem em seu fracasso, na sua queda. O privilégio da linguagem do homem não estaria assim apenas em nomear, em fazer o mundo mudo falar, mas em permitir entrever na linguagem a sua própria mudez, de um ser que não é.

\section{A primazia do estético}

A separação clara entre sujeito e objeto, que caracteriza a modernidade, evidencia a fratura entre as palavras e as coisas, isto é, intensifica o caráter arbitrário e extrínseco - em oposição ao caráter essencial da linguagem adâmica descrita por Benjamin - do signo linguístico. Retomando o vocabulário mítico-religioso tantas vezes empregado pelo filósofo alemão, é possível afirmar, portanto, que o advento da modernidade coincide com uma espécie de 
intensificação da decadência, uma vez que a era da racionalidade humanista se caracteriza, justamente, pela dessacralização do mundo e pelo domínio progressivo da técnica e do pensamento científico sobre a natureza.

A partir do século XIX, entretanto, como ressalta Michel Foucault em As palavras e as coisas (2002), uma série de escritores dão início a um profundo exercício de recuperação dos poderes originais da linguagem. Esses escritores - predominantemente poetas - se preocuparam em reestabelecer aquilo que Foucault chama o caráter mágico da linguagem. Em sua obra "Linguagem e mito", o filósofo alemão Ernst Cassirer descreve esse mesmo processo de desencantamento da natureza pela razão científica e técnica, terminando por enxergar na experiência estética mais um caminho alternativo para a recuperação do universo mítico, original. Segundo Cassirer:

Há, porém, um reino do espírito no qual a palavra não só conserva seu poder figurador original, como, dentro deste, o renova constantemente; nele, experimenta uma espécie de palingenesia permanente, de renascimento a um só tempo sensorial e espiritual. Esta regeneração efetua-se quando ela se transforma em expressão artística. Aqui torna a partilhar de plenitude da vida, porém, se trata não mais da vida miticamente presa e sim esteticamente liberada. ${ }^{\mathrm{xx}}$

Distante mais de um século da revolução romântico-simbolista, Beckett também procura acessar o mesmo universo primordial, e o faz pelas vias da tradução, pensada como experiência predominantemente estética, a partir da qual a linguagem volta-se sobre si mesma e desvela uma essência que, embora caracterizada pela mudez, aponta, na própria impossibilidade de repouso, para o universo mítico da "língua pura".

\section{Referências Bibliográficas}

BECKETT, Samuel. "Letter to Axel Kaun”, 9 Jul 1937. In: The Letters of Samuel Beckett. Martha Dow Fehsenfeld; Lois More Overbeck. 2 Vol. Cambridge: Cambridge University Press, 2009. Vol I: pp.516-21.

. L'Innomable. Paris: Les Éditions de Minuit, 1953. 
. O Inominável. Trad. Ana Helena Souza. Prefácio João Adolfo Hansen. São Paulo, Globo, 2009. Original Francês.

. "The Unnamable”. Trad. Samuel Beckett. IN: Three Novels by Samuel Beckett: Molloy, Malone Dies, The Unnamable. New York: Grove Press, 1955. pp.289-414. Original Francês.

BENJAMIN, Walter. "A tarefa do tradutor". IN: Escritos sobre mito e linguagem. Organização, apresentação e notas de Jeane Marie Gagnebin; Trad. Susana Kampff Lages e Ernani Chaves. São Paulo: Duas Cidades; Ed. 34, 2011. pp.101-119.

. "A linguagem em geral e a linguagem dos homens". IN: Escritos sobre mito e linguagem. Organização, apresentação e notas de Jeane Marie Gagnebin; trad. Susana Kampff Lages e Ernani Chaves. São Paulo: Duas Cidades; Ed. 34, 2011. pp.49-73.

CASSIRER, Ernst. Linguagem e mito. São Paulo: Perspectiva, 2006. Col. Debates.

FOUCAULT, Michel. As palavras e as coisas. Trad. Salma Tannus Muchail. São Paulo: Martins Fontes, 2002.

GENETTE, Gérard. Palimpsestos: a literatura de segunda mão. Trad. Cibele Braga et al. Belo Horizonte: Edições Viva Voz, 2010.

RICEUR, Paul. "La symbolique du mal”. IN: Philosophie de la volonté. vol. 1. Paris: Gallimard, 2009.

WEIDNER, Daniel. "Life after Life: a figure of thought in Walter Benjamin". Disponível em: www.zfl-berlin.org/tl_files/zfl/.../life_after_life.pdf. Acesso em 25/12/2013.

\footnotetext{
i BENJAMIN, "Sobre a linguagem em geral e sobre a linguagem do homem”, p.56.

ii Ibidem, p. 68 .

iii Para Benjamin, "o pecado original é a hora do nascimento da palavra humana, aquela em que o nome não vivia mais intacto, aquela palavra que abandonou a língua que nomeia, a língua que conhece, pode-se dizer: abandonou a sua própria magia imanente para reivindicar expressamente seu caráter mágico, de certo modo, a partir do exterior. A palavra deve comunicar alguma coisa (afora si mesma). Esse é realmente o pecado original do espírito linguístico" ("Sobre a linguagem em geral e sobre a linguagem do homem", p.67)

${ }^{\text {iv }}$ BENJAMIN, “A tarefa do tradutor”, p.110.

${ }^{v}$ Ibidem, p. 102.

vi "Literatura da despalavra" (tradução nossa). BECKETT, Letter to Axel Kaun, 1937 apud Fehsenfeld, 2009 , p. 520.
} 
vii BENJAMIN, "Sobre a linguagem em geral e sobre a linguagem do homem", p.71.

viii Ibidem, p.72.

${ }^{\text {ix }}$ Referência ao nome de uma peça de Beckett, Not I. Não raro aparece, também, essa referência aos seus personagens, como é o caso do "vice-exister [Mahood]" (BECKETT, The Unnamable, p.315).

" BECKETT, The Unnamable, p.413. "as palavras falham" (tradução nossa). A edição utilizada, aqui, foi a obra traduzida pelo próprio autor para o inglês. O bilinguismo e a autotradução são temas centrais e têm uma relação intrínseca com a estética e o projeto literário de Beckett, embora não sejam o foco deste trabalho. Vale ressaltar que nem sempre a passagem selecionada, aqui, encontra correspondente no "original" ou na tradução de Ana Helena Souza para o português, que foi feita do francês. Para não negligenciar a versão francesa e, principalmente, para ressaltar o caráter essencial e peculiar de uma obra extensivamente autotraduzida, apresentamos os dois textos do autor.

xii Ibidem, p.414. "faute de mots, plein de murmures" (BECKETT, L'Innomable, p.259). 'falto de palavras, cheio de murmúrios' (BECKETT, O Inominável, p.183)

xiii Ibidem, p. 304. "mensonges que tout ça" (BECKETT, L'Innomable, p.34). "Mentiras isso tudo" (BECKETT, O Inominável, p.45).

xiv Ibidem, p.314. “tout en étant aussi étrangères" (BECKETT, L'Innomable, p.56). "por serem também estrangeiras" (BECKETT, O Inominável, p.58).

xv Ibidem, p.314. "J'ai à parler, c'est vague. J'ai à parler, n'ayant rien à dire, rien que les paroles des autres. Ne sachant pas parler, ne voulant pas parler, j'ai à parler. Personne ne m'oblige, Il n'y a personne, $\mathrm{c}^{\prime}$ est un accident, $\mathrm{c}^{\prime}$ est un fait. Rien ne pourra jamais m'en dispenser, il n'y a rien, rien à découvrir, rien qui diminue ce qui demeure à dire, j'ai la mer à boire, Il y a donc une mer" (BECKETT, L'Innomable, p.55). "Tenho que falar, não tendo nada a dizer, nada a não ser as palavras dos outros. Não sabendo falar, não querendo falar, tenho que falar. Ninguém me obriga a isso, não há ninguém, é um acidente, é um fato. Nada poderá jamais me dispensar disso, não há nada, nada a descobrir, nada que diminua o que falta dizer, tenho o mar a beber, então há um mar" (BECKETT, O Inominável, p.58).

xvi Ibidem, p.303. “et si je parlais pour ne rien dire, mais vraiment rien?” (BECKETT, L'Innomable, p.31). “e se eu falasse para não dizer nada, mas nada mesmo?” (BECKETT, O Inominável, p.43).

xvii Ibidem, p.414. "je ne le saurai jamais, dans le silence on ne sait pas, il faut continuer, je vais continuer" (BECKETT, L'Innomable, p.262). "não saberei nunca, no silêncio não se sabe, é preciso continuar, não posso continuar, vou continuar” (BECKETT, O Inominável, p.185).

xviii Segundo Weidner, que faz uma análise desse conceito em Benjamin, "a tradução é parte da vida essencial de uma entidade histórica. Sua historicidade não consiste somente no seu lugar histórico original, mas em seus efeitos, no seu fazer parte da história que continua" ("Life after Life: a figure of thought in Walter Benjamin”, p.8)

${ }^{\text {xix }}$ GENETTE, Palimpsestos: a literatura de segunda mão, grifo nosso. 